in some part on the subsequent argument. Nor are the charts altogether in accord with even the extended definition. We note, for example, the inclusion of outbreaks side by side in Kent with a difference of four days, and of two outbreaks in Devon with a fortnight's difference. For December r9I9 and January I920 no fewer than sixteen "initial" invasions are recorded, most of them in the south of England, and in the next ten months the total is brought up to twenty-nine. The elimination of such cases as these by a more rigid definition would materially alter the aspect of the data. Nor is it any answer to this objection to say that if these cases are connected it can only be by the same agency as connects original
British outbreaks with foreign outbreaks. The possible carriage of the virus by birds moving within the country is a different ornithological question from that of carriage from abroad, and it is the latter for which the data are presented and which is discussed in the paper.

We are interested to learn from an editorial note in the Journal that Sir Stewart Stockman is now experimentally investigating the possibility of the infection being carried by birds. The question remains open, and further research may well be useful. Here we can only express the opinion that the evidence put before us does very little towards establishing a prima facie positive case.

\title{
The Utilisation of Volcanic Steam in Italy.
}

$7 \mathrm{HE}$ increased desire for economic independence that accompanied the growth of national sentiment during the War has been shown very clearly in the intensified study and exploitation of natural resources; and the welkin is still ringing with cries of " increase production," "back to the land," and " keep the home-fires burning." Examples of this worldtendency are apparent everywhere : in Central Europe, particularly, brown coal, water-power, and minerals have been greatly developed; in tropical countries, useful vegetable products have been increasingly exploited ; and in many lands the rush for petroleum has

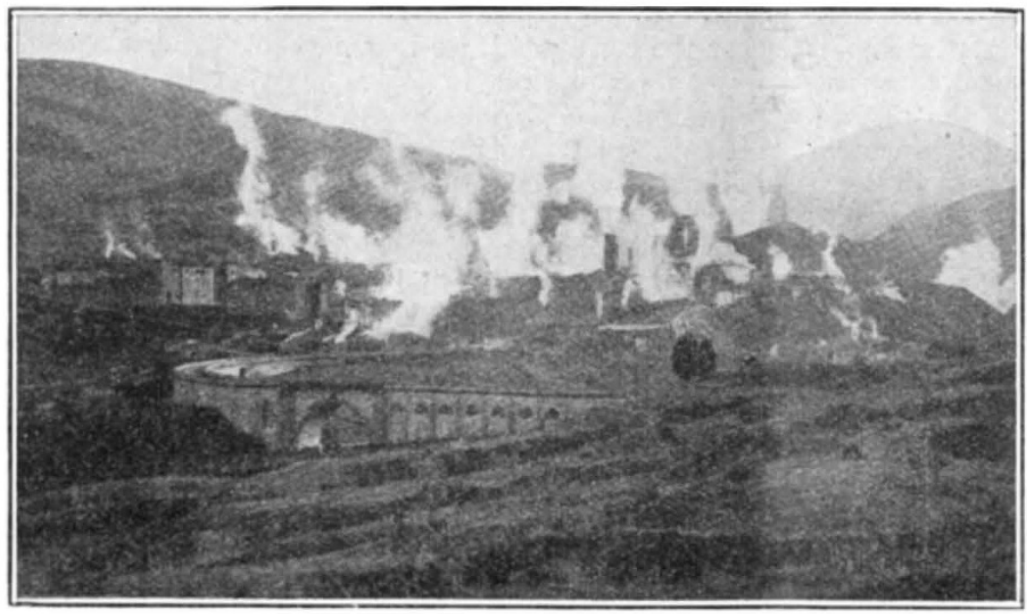

Fig. x.-General view of Larderello.

gathered momentum. Very little, however, has been heard as yet of attempts to utilise the interior heat of the earth, which many believe to be one of the most important potential sources of energy. Only in Italy has a definite and successful effort been made in this direction, namely, by utilising the natural steam which emerges from the earth in volcanic districts. The jets of steam ("soffioni ") and the pools of water, formed in small craters and maintained at boiling temperature by natural steam ("lagoni"), have been known for centuries, but for long were regarded by the peasants as manifestations of unseen and unfriendly powers. The discovery in them of boric acid in 1790 , the extraction of this acid on a commercial scale since $\mathrm{I} 8 \mathrm{r} 8$, and, in particular, the recent pioneer work of Prince Ginori Conti, in association with the Società Boracifera di Larderello, have completely transformed the picture, and revealed a source of wealth which may play an important part, not only in the future industrial development of Italy, but also in that of other countries that are blessed-and at times cursed-with volcanic activity.

The district which has been selected for study and exploitation forms, roughly, an elliptical area of about $2.5 \mathrm{sq}$. miles, lying south of Volterra and from 40 to 50 miles south-south-west of Florence. In this part of Tuscany, works for generating electrical power and for producing boric acid and other chemicals have been erected at Larderello, Castelnuovo, Sasso, Monterotundo, Lago, Lustignano, Sarrazzano, and, to the eastward, at Travale. The works are situated at the bases of hills dividing the valleys of the rivers Cecina and Cornia, and the roads are good, though winding. The volcanic nature of this district is shown by stretches of arid soil, the presence of many "soffioni" and "lagoni," and by the occurrence in their vicinity of sulphur, crystals of calcium carbonate with pseudomorphous growths of gypsum, larderellite (ammonium borate), and sassolinite (orthoboric acid).

For industrial utilisation the supply of steam from "soffioni" is not sufficient, and hence bore-holes, 16 in. diameter and from 200 to $500 \mathrm{ft}$. deep, are sunk and protected from caving by iron tubing. The steam issues at an average pressure of two absolute atmospheres, and at a temperature varying from $100^{\circ}$ to $190^{\circ} \mathrm{C}$., friction against the walls of the bore causing much of the super-heat. Recent drillings have released steam at a considerably higher pressure, and in quantities up to $60,000 \mathrm{~kg}$. (59 tons) per hour. At Larderello the actual available output is above 150,000 $\mathrm{kg}$. per hour from $\times 35$ bore-holes, and generally there is abundant evidence of enormous untapped supplies. The steam, which Prof. $R$. Nasini has shown to be radioactive, contains an average of 0.06 per cent. of boric

$$
\text { NO. } 2828 \text {, VOL. I I } 3]
$$


acid, with a maximum of 0.1 per cent., and about 4 to 6 per cent. by weight of gases, mainly carbon dioxide (over 90 per cent.), but also hydrogen sulphide, hydrogen, methane, oxygen, nitrogen, ammonia, argon and helium.

The first attempt to produce power from natural steam was made in 1897 by using it to heat water in a boiler and feeding a reciprocating engine with the pure steam. In 1905, Prince Conti fed steam direct from a "soffione" into a piston engine, and the result was so successful that in the following year a larger engine was used, and the steam generated was made to drive a dynamo for lighting the works. In 1912 it was decided to erect a $25^{\circ} \mathrm{kw}$. turbo-generator to be worked with natural steam, but owing to fear of corrosion of the turbine blades, and the difficulty of obtaining a good vacuum in the condensers, on account of the presence of the gases mentioned above, this intention was abandoned. Intermediate boilers or evaporators were therefore constructed and used.

The present large power-plant at Larderello was first operated in 5916 , and comprises evaporators, turbo-generators, condensers, and transformers. The evaporators employed, until recently, consisted of vertical aluminium tubes enclosed in a shell of sheet-iron; natural steam circulated round them and the water to be evaporated through them, this water being taken from the

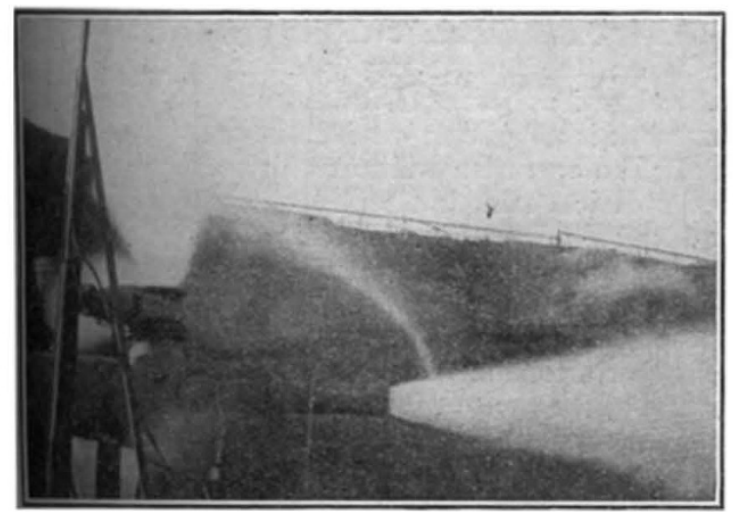

FIG. 3.-A powerful jet of natural steam (" soffione").

condensers or from that formed by condensation of the natural steam.

According to a paper which was read by Prince Conti at the Catania meeting on April 5-I I, I923 of the Italian Association for the Advancement of Science, this type of evaporator has been replaced by another, invented by Signor P. Bringhenti, in which the dissolved gases (v.s.) are separated from the natural steam, thus increasing the efficiency of the condensers. The pure steam, superheated with the aid of natural steam, is fed at a pressure of $\mathrm{x} \cdot 25 \mathrm{~atm}$. abs. into $3000-\mathrm{kw}$. turbo-generators of the Parsons type, of which two are in use and one is kept in reserve. Each unit has a net efficiency of 2500 kw., and generates a 3-phase current at 4000 volts, 50 periods. Step-up transformers of the self-cooling oil type raise this voltage to 16,000 for distribution to the various works, and to $32,000-3^{8,000}$ for transmission to Siena and Florence, Leghorn, Piombino, for use in iron and steel works, and to the pyrites mines at Massa.



Fig. 2.-Works at Larderello: power station and collecting tanks.

The condensers, each with a cooling area of II,300 sq. $\mathrm{ft}$, are placed below the turbines; the cooling water is driven through the tubes by centrifugal pumps and thence to the refrigerating towers. Two hydraulic ejectors are fitted to each condenser, and the condensate is removed by centrifugal pumps. A second power station has recently been erected, at the Lago works, for experimental purposes, including work on the new type of evaporator.

The water containing boric acid is evaporated by natural steam in shallow lead-lined basins arranged on a slightly inclined plane and operated on the countercurrent principle. When the boric-acid content has increased to about 8 per cent., the liquid is cooled and the crude acid, up to 99 per cent. purity, is crystallised out. This acid is then purified by re-crystallisation. At Larderello there is a small production of borax from boric acid and sodium carbonate, and at the Castelnuovo works an output of about Io tons per day of ammonium carbonate.

Looking to the future, it appears more than probable that the production of power and chemicals with the aid of natural steam will not long be confined to Tuscany. Already the volcanic districts of Vesuvius, Etna, and the islands of Eolie (Lipari) are being studied. Outside Italy, like investigations are being pursued in America on the steam springs of California, Chile, and Bolivia; and attention will doubtless be given to similar fields in Alaska, New Zealand, and especially Japan, where such volcanic manifestations are numerous. To Italy, however, will belong the credit of having initiated this method of tapping a supply of energy which, in spite of the attention it has attracted, has been running to waste for centuries, and thus providing yet another method of "utilising the forces of Nature for the benefit of mankind."

$$
\text { NO. } 2828 \text {, vOL. II } 37
$$

